\title{
An Optical Path Length Modulator for Laser Diode Self-Mixing Interference
}

\author{
Xianfeng Hu \\ College of Physical Science and Technology, Sichuan University, Chengdu, China \\ Email: ruirui@vip.sina.com
}

How to cite this paper: Hu, X.F. (2017) An Optical Path Length Modulator for Laser Diode Self-Mixing Interference. Optics and Photonics Journal, 7, 1-5. http://dx.doi.org/10.4236/opj.2017.71001

Received: December 28, 2016

Accepted: January 19, 2017

Published: January 22, 2017

Copyright (C) 2017 by author and Scientific Research Publishing Inc. This work is licensed under the Creative Commons Attribution International License (CC BY 4.0).

http://creativecommons.org/licenses/by/4.0/

\begin{abstract}
Transparent liquid flattening or stretching realizes optical path length modulation. A flat thin seal transparent cavity, one flank is an electromagnetic driving membrane and is filled over with transparent liquid. Vibration of the membrane makes the liquid compressing or stretching, changes the liquid layer thickness, i.e. the optical path length of light through the liquid layer. The liquid layer compressed is equivalent to increase membrane tension. The membrane has higher resonant frequency. The cavity diameter $10 \mathrm{~mm}$ modulation frequency is about $18 \mathrm{kHz}$.
\end{abstract}

\section{Keywords}

Self-Mixing Interference, Optical Path Length, Phase Modulator, Vibration

\section{Introduction}

In general, laser self-mixing interference has only one optical path. It is an advantage in optical arrange, but also is a disadvantage in optical modulating. The phase modulation for self-mixing interference can adopt inserted an AOM or EOM into the optical path, modulating operating current (MOC) or vibrating laser diode modules [1]-[7]. AOM, EOM or MOC may cause optical intensity modulating. Vibrating laser diode modules cannot achieve a high modulating frequency, because the modules are still large and heavy. Like as AOM, if the modulation does not cause modulating structure in optical media, the modulator will do not produce light scattering. Optical intensity modulating will not generate. When the length of optical media is much shorter than the wave length of acoustic wave, a machine wave does not be produced in the media. Also the optical modulating structure does not be formed. The machine vibration only causes the media layer flattening or stretching. Optical path length of light passing through the media layer will be modulated. 


\section{Principle}

The principle of the optical path length modulator is shown in Figure 1. The refraction index of the liquid is $n$. The refractive index of the medium around the container is $n_{a}$. The thickness of container is $L$. When the container is not in the

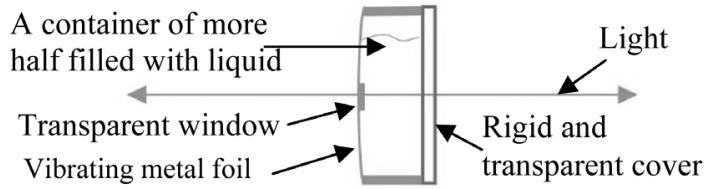

Figure 1. The principle of the optical path length modulator.

optical path, light passing $L$ length, the optical path length is $n_{a} L$. If the metal foil is in sinusoidal vibration, amplitude $A$, frequency $f$. The container inserts in the optical path. The variation of optical path length

$$
\Delta L=\left(n-n_{a}\right) L+\left(n-n_{a}\right) A \sin (2 \pi f t)
$$

On the right side of Equation (1), the first item is a constant, the second item modulates optical path length, modulating amplitude is $\left(n-n_{a}\right)$ A. For selfmixing interference, the variation of optical path length causes phase modulation,

$$
\Delta \delta=\frac{4 \pi\left(n-n_{a}\right) A}{\lambda} \sin (2 \pi f t)
$$

If $\left(n-n_{a}\right)$ far smaller than 1, the metal foil vibrating amplitude needs bigger to achieve a certain degree of phase modulation, which is difficult for high frequency vibration. Although modulation frequency of the modulation method is far less than the modulation frequency of AOM and EOM [1] [2], it can be higher than modulation frequency of light source vibration method [6] [7].

The container inserting optical path may reflect light. Let the transparent window parallel the rigid and transparent cover, and optical path length of the container is nearly equal to an integral multiple of the laser wavelength, or optical length of laser diode resonator. Such arrangement can reduce the light reflection.

Sound speed in liquid is about hundreds to more than 1000 of meters per second. The geometric thickness of the container is about $1 \mathrm{~mm}$. The metal foil of dozens of $\mathrm{kHz}$ vibration stirs the sound wave, which wavelength is much larger than the container's geometry dimensions. A modulated structure should not be provoked in a liquid of the container. If metal foil vibration amplitude is in the laser wavelength scale, the flattening or stretching of the liquid little affects light absorption in the container. Optical intensity modulating does not generate.

\section{Structure}

The structure of the optical path length modulator is shown in Figure 2. The driving apparatus of the metal foil is similar to an internal magnetic type speaker. The moving coil is bonded on the left side of the metal foil, the transparent 


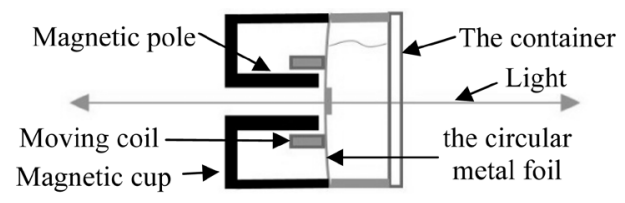

Figure 2. The structure of the optical path length modulator.

window is on the other side. The moving coil inserts into a magnetic cup, on whose center there is a hollow permanent magnetic pole. Then the magnetic cup and the container are bonded by epoxy resin. The moving coil weight is about $0.05 \mathrm{~g}$. The transparent window weight is about $0.01 \mathrm{~g}$. Surface density, weight and radius of the circular metal foil are about $0.0893 \mathrm{~g} / \mathrm{cm}^{2}, 0.07 \mathrm{~g}$ and $0.525 \mathrm{~cm}$, respectively. The liquid in the container is clock oil, whose refractive index is about 1.4870, measured by Abbe refractometer.

Using self-mixing interference technique measures the vibration magnitude and resonant frequency of the circular metal foil. The feedback lights respectively come from the transparent window on the circular metal foil and a stationary reflection surface behind the container for unfilled and filled with liquid. The vibration frequencies of the circular metal foil on the container unfilled with liquid are shown in Table 1. $f_{0}$ is resonant frequency. $M$ is resonant magnitude how much is fringe number. $V_{p p}$ is peak-peak value of excitation source. $f_{1}$ is vibration frequency at which vibration magnitude is one interference fringe. $T_{r}$ is transmission rate. $V_{s p p}$ is magnitude of self-mixed interference signal. There is not any another resonant frequency in the interval of $2 \mathrm{kHz}$ to $42 \mathrm{kHz}$.

Table 1. The frequency and magnitude of the circular metallic foil on the container before filled with liquid.

\begin{tabular}{cccccc}
\hline$f_{0} / \mathrm{kHz}$ & $M$ & $V_{p p} / \mathrm{V}$ & $f_{1} / \mathrm{kHz}$ & $T_{r}$ & $V_{s p p} / \mathrm{V}$ \\
\hline 8.60 & 4.5 & 8.6 & 13.6 & 0.939 & 4.77 \\
\hline
\end{tabular}

The vibration frequencies and amplitude of the circular metal foil on the container half-filled with liquid are smaller than the ones of unfilled with liquid. But the vibration frequencies of filled over with liquid are approximately twice of unfilled with liquid. The vibration amplitude is smaller than the unfilled with liquid, shown as Table 2.

Table 2. The frequency and magnitude of the circular metallic foil on the container after filled over with liquid.

\begin{tabular}{cccccc}
\hline$f_{0} / \mathrm{kHz}$ & $M$ & $V_{p p} / \mathrm{V}$ & $f_{1} / \mathrm{kHz}$ & $T_{r}$ & $V_{\text {spp }} / \mathrm{V}$ \\
\hline 18.00 & 2.0 & 8.6 & 19.00 & 0.939 & 4.77 \\
\hline
\end{tabular}

The container half-filled with liquid, the circular metal foil vibrates to flatten or stretch the liquid in the container, but not to compress the liquid, whose mass and viscosity impede the circular metal foil vibration. The container filled over 
with liquid, the circular metal foil vibration must compress, as well as flatten or stretch the liquid, whose mass and viscosity smaller affect the vibration. For phase modulation of self-mixing interference, the transparent window on the circular metal foil only needs displacement about 0.5 laser wave length [6] [7]. The geometric thickness of the container is about $1 \mathrm{~mm}$. The laser wave length is $650 \mathrm{~nm}$. If the vibration of the circular metal foil is symmetrical, the volume variation of the liquid is about $8 \times 10^{-5}$, that needs a large driving force. The vibration of the circular metal foil should be asymmetrical. The displacement toward the liquid side is smaller than toward the air side. When driving current is applied to the moving coil, the coil itself will be heated, and thermal conduction through the circular metal foil also heats the liquid. The liquid is in the hot pressure status. The liquid compressed, its elasticity appears. The tension per unit length of the circular metal foil equivalently increases, therefore, for the vibrating system consisted of circular metal foil and liquid in a closed container, the resonant frequency enlarges.

\section{Application}

The optical path length modulator, which prototype is shown in Figure 3(a), inserts between laser diode and target, as shown in Figure 3(b). In order to further reduce reflective light of the modulator into the laser diode, the modulator



(a)

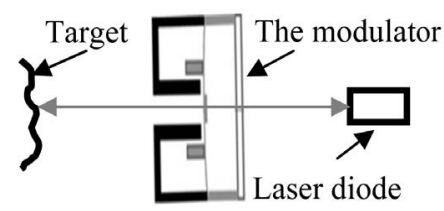

(b)

Figure 3. Prototype (a) and using scheme(b) of the modulator.

is slightly tilted. The vibration frequency of modulator is about $18 \mathrm{kHz}$. Using USBee DX Pro acquiring modulation signals [8], Fourier transform spectrum components extraction methods [6], and LabVIEW programming demodulate signal, and display the waveform and vibration spectrum [8]. When the target is a 2.25 -inch speaker excited by a $20 \mathrm{~Hz}$ square wave signal, vibration waveform is shown in Figure 4. From the waveforms of damped oscillation can distinguish vibration magnitude of about $\lambda / 4$. The speaker vibration spectrum is shown in Figure 5.

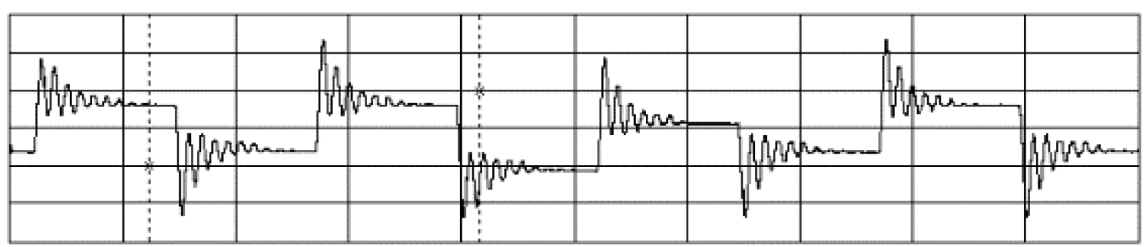

Figure 4. The speaker vibration waveform. Horizontal scale: $20 \mathrm{~ms} / \mathrm{Div}$, vertical scale: 1 $\lambda /$ Div. 


\begin{tabular}{|l||l|l|l|l|l|l|l|l|l|l|}
\hline \hline & & & & & & & & & & \\
\hline & & & & & & & & & & \\
\hline & & & & & & & & & \\
\hline
\end{tabular}

Figure 5. The speaker vibration spectrum. Horizontal scale: $100 \mathrm{~Hz} / \mathrm{Div}$, vertical scale: au/Div.

\section{Conclusion}

The modulator can achieve optical path length modulation. The modulator filled over with liquid has higher modulating frequency. The modulator does not induce light intensity modulated. The modulating frequency is still too low. To increase modulating frequency, mass and radius of the driving coil and the metal foil need further decrease. Selecting a liquid of bigger refractive index, the modulator did not need a large vibrating amplitude, could achieve the required modulation amplitude and was also conducive to increase modulation frequency.

\section{References}

[1] Otsuka, K., Abe, K., Ko, J.Y. and Lim, T.S. (2002) Real-Time Nanometer-Vibration Measurement with a Self-Mixing Microchip Solid-State Laser. Optics Letters, 27, 1339-1341. https://doi.org/10.1364/OL.27.001339

[2] Guo, D.M., Wang, M. and Tan, S.Q. (2005) Self-Mixing Interferometer Based on Sinusoidal Phase Modulating Technique. Optics Express, 13, 1537-1543. https://doi.org/10.1364/OPEX.13.001537

[3] De Groot, P.J., Gallatin, G.M. and Macomber, S.H. (1988) Ranging and Velocimetry Signal Generation in a Backscatter-Modulated Laser Diode. Applied Optics, 27, 4475-4480. https://doi.org/10.1364/AO.27.004475

[4] Tucker, J.R., Rakic, A.D., O’Brien, C.J. and Zvyagin, A.V. (2007) Effect of Multiple Transverse Modes in Self-Mixing Sensors Based on Vertical-Cavity Surface-Emitting Lasers. Applied Optics, 46,611-619. https://doi.org/10.1364/AO.46.000611

[5] Norgia, M., Giuliani, G. and Donati, S. (2007) Absolute Distance Measurement with Improved Accuracy Using Laser Diode Self-Mixing Interferometry in a Closed Loop. IEEE Transactions on Instrumentation and Measurement, 56, 1894-1900. https://doi.org/10.1109/TIM.2007.904551

[6] Wang, M. and Lai, G.M. (2001) Displacement Measurement Based on Fourier Transform Method with External Laser Cavity Modulation. Review of Scientific Instruments, 72, 3440-3445. https://doi.org/10.1063/1.1386898

[7] Hu, X.F. (2011) External Cavity Modulation of Laser Self-Mixing Interference by Light Source Vibration. Journal of Sichuan University (Engineering Science Edition), 43, 143-148. (In Chinese)

[8] Hu, X.F. (2016) Measuring Vibration Using Laser Self-Mixing Interference. Physics Experimentation, 36, 13-14, 18. (In Chinese) or https://www.researchgate.net (In English) 
Submit or recommend next manuscript to SCIRP and we will provide best service for you:

Accepting pre-submission inquiries through Email, Facebook, LinkedIn, Twitter, etc. A wide selection of journals (inclusive of 9 subjects, more than 200 journals)

Providing 24-hour high-quality service

User-friendly online submission system

Fair and swift peer-review system

Efficient typesetting and proofreading procedure

Display of the result of downloads and visits, as well as the number of cited articles

Maximum dissemination of your research work

Submit your manuscript at: http://papersubmission.scirp.org/

Or contact opj@scirp.org 